\title{
Balancing Research Productivity and Teaching by Faculty in Higher Education: A Case Study in the Philippines
}

\author{
Prema Gaikwad \\ Adventist International Institute of Advanced Studies
}

Environmental and personal characteristics are known for its contribution to research productivity of faculty in HE. Based on the theories of cognitive motivation and social motivation, this qualitative case study examined the individual and institutional conditions that impacted faculty research productivity, and discovered how faculty balance research productivity and teaching. The mechanisms used by the faculty of a private institution of $H E$ in the Philippines in coping with research production were explored. The findings pointed to institutional support through time off for research, financial and resource back-up, and incentives. Personal aspects of this process included advancement of knowledge and research skills, recognition, and networking opportunities.

Keywords: faculty, research, teaching, balance, higher education, cognitive motivation theory, social cognitive theory, research gap, case study, Philippines

\section{INTRODUCTION}

Knowledge production is one of the prime missions of higher education institutions (HEIs) whether they are public or private universities. This mission is carried out through the research productivity of research students and faculty. Faculty members, however, find themselves as the major "burden-bearers" of this process and are typically pressured and mandated to carry out research production (Blackburn, Bieber, Lawrence, \& Trautvetter, 1991; Commission on Higher Education, n. d). In recent years, academics tend to experience the demand for balancing teaching and research by their institutions (Lapoule \& Lunch, 2018) even as they juggle the other aspect of the tripartite - service. Faculty who are employed primarily for teaching may find the need to consider research production as equally important to remain employed. However, even as the familiar "publish or perish" slogan looms in their minds, teaching, student advising, and community service often take priority in terms of time and effort of faculty members, especially in the private sector with fewer human resources.

Private universities especially tend to focus more on teaching and quality education than research production (Khan, 2017). Research often takes a back-burner for many-a-faculty when circumstances take the better off them, in terms of time and resources. Considering the investment in time and effort to do research, often a sense of learned helplessness sets in, as Bandura (1977) predicted, when faculty members give up trying because "they lack a sense of efficacy in achieving the required behavior" (p. 204).

Past studies have shown that globally, in the HE settings, the bulk of publication is carried out by a small group of academics (Teodorescu, 2000). Studies have also shown that research is a complex or multidimensional activity with resultant benefits for all the stakeholders: faculty, students, institution, and society 
(Gregorutii, 2011). In a typical HEI, research production brings extended recognition and benefits to faculty while recognition for teaching does not go beyond the classrooms and institutions at large. Students benefit from faculty research primarily when they collaborate with faculty in conducting and publishing research. Regarding the benefits to HEIs, faculty research productivity is typically regarded as an indicator of its academic performance and "calculation of university rankings" (Jung, 2012, p. 1). Society benefits from the knowledge production and from research collaboration of HEIs with other organizations.

Research is considered a major quality criteria for HEIs, leaving faculty with little option but balance research along with teaching and service related responsibilities. Tenure and ranking issues are also related to research productivity of faculty. This context of increasing demands on faculty to balance teaching and research and its implications for HE in the context of private sector is the focus of this study.

\section{LITERATURE REVIEW AND THEORETICAL SOLUTION}

Reviewing the literature on faculty research productivity, several important connections seem to contribute for the theoretical framework of this study. Notable is the academic literacies theory (Lillis \& Scott, 2007) which view academic writing as a social practice, which include "power relations, identity, and ideologically inscribed knowledge construction" (Nygaard, 2015, Introduction section, para. 3) which Lillis (2003) and Lea and Street (2006) also attest to. Just as much "high stakes" the activity of academic writing is for students, it is also the same for faculty, in higher education (Lillis \& Scott, 2007). Another perspective is brought by Fairweather (2002) that teaching and research are seen as mutually reinforcing. Fairweather (2002) has come up with a tenet that each faculty member can be a "complete faculty member" by the simultaneous productivity "in both teaching and research" (p. 27). However, no conclusive answer exists in research literature about the relationship between faculty research and teaching effectiveness (Khan, 2017).

Looking for theoretical solutions that can help understand the issue of faculty research productivity, certain postulates were found. One of them is the claim that behavior is the result of (a) self-perception that interacts with environment (Bandura, 1986) and (b) self-knowledge and social knowledge that generate the motivational basis of actions (Blackburn \& Lawrence, 1995). In other words, how people perceive and process their own abilities within the context seem to matter (Jacob et al., 2020). Also, the environment where faculty works impacts their ability to produce research (Jacob et al., 2020).

Numerous studies have been conducted on faculty research productivity that can be traced from mid 1970's (Nygaard, 2015) and with detailed information (Blackburn, Lawrence, Bieber, \& Trautvetter, 2011). An interesting finding of these studies is that both environmental and personal characteristics seem to contribute to research productivity of faculty in HE (Gregorutti, 2011). But these past studies lack theoretical bases. This lack of theoretical bases for studies on research productivity has been addressed by Gregorutti (2011). He used the cognitive motivation theory (Blackburn et al., 1991) and social cognitive theory (Bandura, 1991) in his own study. The cognitive motivation theory states that perceptions of individuals on their individual abilities and interests bear upon their perceptions of the institutional priorities, thus causing them to engage considerably in activities supported by the organization and less engaged in other activities. The social cognitive theory postulates that individuals act upon and set out to achieve outcomes by taking stock of their belief in environmental and personal factors. The present study is also based on these two theories - cognitive motivation theory and social cognitive theory - which can be summarized as behavior being "a product of dynamic interaction between self-and environmentalperceptions" (Gregorutti, 2011, p. 29). Strengthening of the theoretical bases for faculty research productivity was recommended by Gregorutti (2011) to fill the theoretical gap (Miles, 2017) in this area.

Identifying other types of research gaps (Miles, 2017) related to the present study, four moremethodological gap, knowledge gap, population gap, and geographical gap - were found in literature. A search of literature has found a plethora of quantitative studies, especially in the area of faculty research production. Studies identified include the following: a survey study to find the factors that contribute to higher or lower faculty research output (Heslie \& Lee, 2011); a mixed methods study by Gregorutti (2011) of aspects that produce best research productivity and suggested research using qualitative designs to 
"uncover dynamics of research that occur in universities" (pp. 107, 108); a content analysis by Wa-Mbaleka (2015) to explore factors that limit faculty research productivity; a longitudinal study of department climate and faculty productivity (Sheridan et al., 2017); and a survey study of the effects of institutional policies and characteristics on research productivity (Nguyen, Nguyen, \& Dao, 2021). The present study employed a qualitative case study to understand faculty perceptions on research productivity.

Regarding knowledge gap, few studies have focused on the interaction of individual and institutional characteristics on research productivity (Blackburn \& Bentley, 1993; Nygaard, 2015). Blackburn and Bentley (1993) studied the importance of both institutional and individual goals; Williams and Kotrlik (2004), found the importance of perceptions related to organization priorities and individual's own abilities; and Gregorutti (2011) studied the "personal and environmental motivational variables on research output" (p. 29) of faculty members. Gregorutii (2011) found that self-knowledge of faculty members was the strongest contributor for research productivity.

The present study also found a definite population gap and addressed this by focusing on the faculty a private HEI. A search of literature resulted in scarce studies on private HEIs. Examples of the few available studies on private HEIs include that of Abouchedid and Abdelnour (2015) and Gregorutti (2010). In terms of geographical gap, studies are found in the Philippines that consider teaching (Medallon, 2012; Rosaroso, Dakay, \& Sarmiento, 2015) or research productivity (Acar, 2012; Narbarte \& Balila, 2018) separately pointing to sparse research base on faculty balance of research and teaching. With these areas of research gaps, the present study explored ways to add to the knowledge base in these areas.

The purpose of the study was to examine the individual and institutional conditions that positively or negatively impact faculty research productivity, and to discover how faculty balance research productivity and teaching. The results of the study contribute in creating an advantageous combination of individual and institutional conditions that will result in greater faculty research productivity in higher education, especially in the context of private institutions. The following research questions guided the study:

1. What makes faculty members produce and publish more research?

2. What personal characteristics foster or inhibit faculty research production?

3. What institutional characteristics foster or inhibit faculty research production?

4. How do faculty members balance the teaching and research production opportunities of the institution?

A couple of terms that are used in this study need to operationally defined. The term "faculty" refers to the teachers in a private HEI in the Philippines. Faculty "research productivity" is identified as the publications of the faculty in terms of document submissions for academic institutional academic awards, in the preceding two years of this study. These publications are listed in the institutional website as evidence of faculty research productivity.

\section{METHODOLOGY}

This research was designed as a single, holistic (Yin, 2018), instrumental (Stake, 1995), and explanatory (Creswell \& Poth, 2018) case study. As a single case study, its focus or the case of the study was the process of managing two of the primary professional responsibilities of faculty members: research productivity and teaching. The bounded system consisted of faculty, and pertinent documents and artifacts. Since the data was analyzed in totality, this is holistic case study. This case study was also of the instrumental type since the main intent was to shed light on the issue of faculty productivity. To obtain a deeper understanding of the case - the process of balancing research productivity and teaching of the faculty, data was gathered using several tools, which will be described subsequently.

\section{The Setting}

This qualitative case study explored the mechanisms used by the faculty of a small-size, private, doctorate-granting HEI in the Philippines in coping with research production even as they grapple with teaching and other professional responsibilities. This institution offers exclusively graduate programs in selected disciplines. The HEI also offers programs through online and distance learning centers. It is a 
residential campus where graduate students from more than 60 countries reside (mostly with their families as well). The faculty, 42 of them at the time of the study, are also multinational.

\section{Data Collection}

Data collection tools consisted of an online survey, two individual interviews, two focus group discussions, documents, and literature. The online open-ended survey had a set of 10 questions and an additional five items related to background information (adapted from Gregorutti, 2011, permission granted from the author). The purpose was to elicit faculty view-points regarding research productivity in general. The 10 questions used in the online survey are found in the appendix.

In-depth semi-structured interviews were conducted face to face with two faculty members who have demonstrated high research productivity. Each of these in-depth interviews had a duration of 60 to 90 minutes and was conducted in person following the health protocols during the pandemic. The participants were selected using purposive sampling. The selection criteria for the two faculty members were (a) fulltime teaching faculty member, (b) someone who has been at the HEI for at least two years, and (c) having high research productivity as evidenced through institutional documentations (faculty publication awards documentation). Permission to audio record the interviews was taken from the participants.

Two sets of FGDs were also conducted. The first FGD consisted of five members and the second of seven members (different from the members chosen for individual interviews). One of the FGD groups was composed primarily of high research productivity faculty members and the other group composed seven faculty members who were moderately active in their research productivity. Both the groups were encouraged to share information related to their research productivity and balancing it with teaching. Any differences in their responses were seen are useful contributions to the findings of the study. Both the FGDs contributed equally to the study. The common selection criteria for the members of FGDs were (a) fulltime teaching faculty member and (b) someone who has been at the institution for at least two years. Each FGD session took 60 to 90 minutes. These sessions were conducted through the Zoom virtual platform due to the restrictions in physical meetings during pandemic situation. The sessions were recorded with the permission of the participants.

Official documents and selected research artifacts of faculty were used to triangulate data. Permission was obtained from the participants to access these documents which were available in the public domain of the institutional website. Table 1 (see Appendix) provides the data triangulation matrix for this study. The process of conducting the research is summarized as follows: (a) permission from the HEI, (b) clearance from institutional ethical review board, (c) sending the online open-ended survey to the faculty, (d) interviews of two high research-productivity faculty, (e) FGDs using Zoom. Pertinent documents related to faculty research production were accessed with permission from the participants.

\section{Ethical Considerations}

The following ethical considerations were taken into account during the study:

1. The study plan was cleared through the researcher's ethical review board and the gatekeepers of the study context.

2. Participants were asked for informed consent for both the online open-ended survey and the individual interviews. The informed consent form was sent in advance through the email to the faculty. Those who consented also participated in the online survey. In the case of individual interviews, a consent form was signed by each participant. Permission to audio record the personal interviews and to access research production indicators of documents and artefacts was taken from these selected faculty.

3. The study ensured voluntary participation of the faculty. No specific incentive was part of the study; however, the knowledge of outcome of the study was seen as of high value and interest to the participants.

4. No physical or psychological discomfort were experienced by the participants of this study. The response time-frame of the online survey was 20 to 30 minutes and personal interviews 
and FGDs 60 to 90 minutes. A cordial yet professional condition was maintained through these sessions.

5. Participants and the institution were ensured of confidentiality and anonymity. Information related to the study was to be only utilized in the context of the research write-up and any professional presentations and publications as planned. Personal or institutional identity was not revealed in any manner as pseudonyms were used while reporting the study.

\section{Data Analysis}

Analysis of data was carried out in various stages: First, the online open-ended surveys were analyzed using the first 10 questions that contributed to the research questions. Twelve faculty responded to the 15item online open-ended survey. Ten of the questions were pertaining to research and teaching, while five last items provided demographic information. Second, the two individual interview data were transcribed, given for member check, and prepared for analysis. Third, the two FGDs data were transcribed and prepared for analysis. Fourth, the available institutional documents pertaining to faculty publications were searched for and checked for corroborating the data. Finally, the data obtained from literature was prepared for theoretical triangulation.

Certain demographic data for addressing came from the online survey. This data was automatically summarized in Google Form which allowed for convenient analysis. The demographic information from the survey revealed that more male $(80 \%)$ responded to the survey. The academic ranks of the respondents were professors and assistant professors - $45.5 \%$ each and associated professors- $9.1 \%$. A little over half $(54.5 \%)$ of the faculty indicated teaching part time with a similar percentage indicated carrying out administrative responsibilities as well as teaching. This data pointed that many of the faculty also had administrative responsibilities.

The data from the individual interviews of two faculty who demonstrated proficient publications, and the two faculty FGDs were analyzed using content analysis. Data analysis had to be carried out in a highly personalized manner, as I am the main research instrument for this qualitative research. I used interactions and immersion with the data resulting in finding patterns, themes or categories which is the essence of qualitative data analysis. The stages of data analysis included the use of open coding in the form in vivo coding (emerging from the data) and axial coding where relationships are found among the categories identified during open coding. This is the model of data analysis by Corbin and Strauss (2015) which is the constant comparative analysis leading to the final step of using selective coding creating the story line of the findings. The following is a description of the findings of the study.

\section{FINDINGS}

The results of the study are based on the four research questions. Each of these questions served as themes as data provided the supporting codes which were eventually broadly grouped as categories. The quotations of participants are taken from the transcription notes that was part of the data management for this study. The findings are discussed below under the main theme generated for the question.

\section{The Reasons for Publishing}

Faculty shared reasons why they engage in writing and publishing, through the open-ended survey. Five main reasons for publishing emerged from the data which were (a) knowledge, (b) research skills, (c) teaching, (d) status and recognition, and (e) network opportunities. A brief description of these faculty responses follows.

\section{Knowledge}

The most frequently mentioned reason for publishing their works is the desire for adding to the knowledge base, both personal and general. Faculty expressed this desire through such phrases as, "increasing my knowledge," "personal development and knowledge," "sharing of knowledge," "contribute 
to the building of knowledge," and "knowledge advancement." Thus, an inward and outward lookout for knowledge advancement is seen as the prime reason for publishing.

\section{Research Skills}

A more personalized need was expressed in these responses. Responses such as "strengthen my research skills," "exercise research skills," and "provoke critical thinking," pointed to the desire for selfimprovement in this area. The faculty viewed activities involved in publishing contributing their professional growth.

\section{Teaching}

A reason that was more frequently mentioned was the contribution of research publication to teaching. The remarks included "better teaching," "provide a resource," "improving teaching by discovering new resources and ideas," "shape and improve my teaching resources." The contribution of research to teaching is seen as valuable by the faculty.

\section{Status and Recognition}

Several faculty considered the desire for tenure and advancement as motivating them to publish. This view is evidenced in statements such as, "personal advancement," "enhance status," "gaining publications for CV," and "to be recognized in the academic field." Considering the institution's mandatory requirements for ranking, this reason seems understandable.

\section{Network Opportunities}

Publication is seen as an avenue for professional networking. Faculty reported this reason through expressions such as, "I want to collaborate with colleagues and students," "networking and linkages," "benchmarking," and "entering the dialogue with peers in the field." This outward look of the faculty through publishing is obvious in these responses.

\section{Personal Characteristics}

The second research question addressed the personal characteristics that foster or inhibit faculty research productivity. Four typical characteristics of a proficient faculty researcher emerged (a) selfmotivation, (b) collaboration, (c) family structure and support, and (d) time management. The characteristics that inhibit faculty research production were found to be (a) giving priority to teaching, (b) inability to manage time, (c) insufficient skills in teaching or research. These two segments of the response are discussed below.

Related to personal characteristics that foster faculty research productivity, positive responses from the open-ended survey and the details provided during individual interviews and FGDs pointed to evidences such as published articles and book chapters, supporting student research, and incorporating student research in classes. Evidence of self-motivation was clearly evident in statements such as "I do research because I like it," and it comes from "my interest" accompanied by exciting facial expressions and gestures. Collaboration was claimed as a success trait as faculty described the benefit of research collaboration with colleagues and students. "We co-publish" was seen as a way to go. A faculty member also responded, "I am also part of different dialogues with specialists in my area of research and in my field." Family structure and support such as having "no children at home" and "house help" were seen as helpful and convenient in facilitating research endeavors. Time management was seen crucial for research activities. "I make time for what I want to do," "being intentional with time," were comments that pointed to this aspect.

Personal characteristics that inhibit research production primarily included giving priority to teaching, from the responses of the faculty. Typically, small-sized private universities give preference to teaching over research, due to the limited number of faculty in the roster (to take turns in teaching, as possible in large universities). Inability to manage time through "procrastination" was identified as another reason for the slack in research activities. Some of the faculty attributed their own insufficient skills in either teaching or research. The need for mentoring was seen as helpful. 


\section{Institutional Characteristics}

The third research question addressed the institutional characteristics that contributes or hinder faculty research productivity. The faculty attributed their research success to (a) material resources, (b) human resources, and (c) research culture. The faculty highly valued the institutional provisions of personal computers, good internet connections, well-equipped library, research funds along with writing leave (of two weeks per year). The provision of human resources that supported faculty research acknowledged were graduate assistants and faculty development through offering research training workshops. The institutional research culture where colleagues who encourage and share ideas related to research was appreciated by faculty. They also attributed the cross-cultural experiences in classes and campus life as providing research ideas.

Institutional characteristics seen as hindering publishing were also shared by faculty. Seven areas were identified as follows: (a) heavy teaching load, (b) inadequate research support, (c) insufficient time off for research, (d) having administrative responsibilities along with teaching, (e) unclear institutional research agenda, (f) lack of research leadership, and (f) scarce institutional avenues to publish. Comments such as "time off from teaching and other responsibilities," "sufficient time like a sabbatical," "having more free time dedicated for research," pointed to these areas that were seen as needing more attention by the institution. Needing more motivation was also mentioned as helpful research productivity.

Varied suggestions were shared by faculty for improving the institutional support for research. Needing to "develop research centers in different academic and professional areas," was a substantive suggestion. Institutional support in publishing and finding research partners was also suggested. Providing opportunities to integrate research in courses, and conducting collaborative research with colleague and students were suggested. The need for additional time for research that was a spill-off from the previous question continued to be shared by faculty.

Departments were seen as supporting research by $40 \%$ of the faculty. Related to the promotion of research, faculty commented, "no one knows who is writing/researching, what to present where," "no longterm vision," and "we hardly talk about faculty research unless it is supervision of the students" were the responses. About departmental mentoring of research, "too new to judge," "lacking in mentoring for faculty research productivity" came as responses.

Positive responses were also emerged for this question. "In departmental meetings, we always talk about the research progress," "We conduct trainings on a regular basis. We also endeavor to provide at least one term when faculty do not teach." On response pointed to the support of the department chair as "ready to accommodate things to favor research." Some amount of institutional support is evidenced in these responses.

\section{Balancing Teaching and Research}

The fourth research question addressed the question, "How do faculty members balance the teaching and research production opportunities of the institution?" At the outset, the perceptions of faculty about the issue of balancing research productivity and teaching provided a rather bleak picture. The online survey pointed out that most $(72.7 \%)$ respondents considered themselves not balancing research productivity and teaching. This response may not be representative of the entire faculty and could point to their own desire to do better than what they do now. The overall reasons such as, "too much demand - teaching, meetings, etc.," "with only two weeks allocated for writing, this is a joke for serious research and publishing," "not very well trained in doing research," pointed to the busy life in academe and the lack of expertise in research writing. Obviously, these drawbacks implied both institutional and personal aspects that stood in the way of research productivity.

Following up with faculty who were found to be engaged in research productivity, through interviews (personal in-depth and FGDs), three ways that faculty seem to balance research productivity and teaching were found: (a) connecting teaching and research, and valuing both, (b) collaborating, and (c) focusing research within the area of specialty. Those who considered themselves as balancing research productivity and teaching shared the reasons as, "because I have the goal to write a paper per quarter, and publish it if possible," "both [referring to research and teaching] are important." Specific personal and institutional 
aspects were also mentioned. Personal aspects that were conducive to research productivity included the following: (a) working longer hours, (b) doing research with a team, (c) connecting professional tasks such as teaching and advising student dissertations, and (d) focusing on research areas within the area of specialization. The use of institutional support in balancing research productivity and teaching included (a) making use of the writing leave, (b) not taking overload in teaching, and (c) using graduate assistants.

\section{DISCUSSION}

The data from this study point to a major conclusion - faculty research productivity is based on both individual behavior and institutional support. This finding is similar to that of Gregorutti (2011). The personal characteristics of self-motivation, collaboration, family structure and support, and time management stood out as important to research productivity. Motivation for research productivity comes from various factors such as personal satisfaction, building network, rewards and incentives, and ranking as the study of Narbarte and Balila (2018) also suggested. Collaboration, a "scholarly behavior," is evidenced through effective network within and outside the university (Gregorutii, 2011) just as the present study point to. In terms of family support, the study of Sax, Hagedorn, Arredondo, and Dicrisi III (2002) has shown that family-related responsibilities seem not to come in the way of scholarly productivity even among married women. In the present study which includes women faculty (though only $20 \%$ ), the women were of higher professorial rank (professor, associate professor or assistant professor), who found ways to cope up with family demands and seek support. Time management was seen as important by the faculty who are self-motivated while typically faculty who do not participate in research productivity consider this as an inhibiting factor (Wa-Mbaleka, 2015).

Institutional support that were helpful for faculty research were resources and recognition, research training and culture. The study of Aithal (2016) has pointed to several of these and more institutional efforts to improve faculty productivity. Other areas of institutional hindrances to research productivity were identified that makes research productivity challenging for the faculty. Taking into account that institutional aspects are more flexible to changes (Jung, 2012), the personal characteristics stand out as important for research productivity issues. Several mechanisms for balancing research and teaching were identified by faculty, such as, integrating research with teaching and area of expertise, collaboration with students and colleagues and making deliberate personal choices that upholds research as well as teaching.

Thus, balancing research productivity and teaching is seen as possible in spite of less favorable environmental situations. The personal commitment of faculty was the strongest contributor for research productivity as also was found by Gregorutti (2011). Motivated faculty engage in actions that translate into publications such as scholarly journals articles and books (Jacob et al., 2020) which the results of this study point to. In summary, this study agrees with the cognitive motivation theory (Blackburn et al., 1991) as well as the social cognitive theory (Bandura, 1991). This implies that faculty productivity is a result of "interactions between their perceptions of their capabilities and their environment" (Gregorutii, 2011, p. 29).

This study resulted in recommendations to small-sized private HEIs in terms of the need for research centers, institutional publishing avenues, providing realistic time and resources for research, having a clear institutional research agenda, promoting research endeavors, and improving hiring practices of facultythose with research expertise. Recommendations to faculty include engaging in scholarly activities that will result in publications (for example, presentations in research conferences) and increasing collaborative research with colleagues and students. Follow-up studies on medium and large HEIs and quantitative studies on factors affecting the balancing of faculty research productivity and teaching in small-sized HEIs are suggested. 


\section{REFERENCES}

Abouchedid, K., \& Abdelnour, G. (2015). Faculty research productivity in six Arab countries. DOI 10.1007/s11159-015-9518-5

Acar, B. (2012). Research capability of the selected public and private higher education institutions in Cebu City, Philippines. IAMURE International Journal of Education, 4, 58-101. doi: http://dx.doi.org/10.7718/iamure.ije.v4i1.449

Aithal, P.S. (2016). How to increase research productivity in higher educational institutions: SIMS model. Retrieved from https://mpra.ub.uni-muenchen.de/71750/1/MPRA paper 71750.pdf

Bandura, A. (1977). Self-efficacy: Toward a unifying theory of behavioral change. Psychological Review, 84(2), 191-215. Retrieved from https://www.academia.edu/3331051/Self_efficacy_toward_a_unifying_theory_of_behavioral_cha nge

Bandura, A. (1991). Social cognitive theory of self-regulation. Organizational Behavior and Human Decision Processes, 50, 248-87. doi: 10.1016/0749-5978(91)90022-L

Blackburn, R.T. (1991). Faculty at work: Focus on research, scholarship, and service. Research in Higher Education, 32(4), 385-413. Retrieved from

https://www.researchgate.net/publication/30844376_Faculty_at_work_Focus_on_research_schola rship_and_service_Research_in_Higher_Education_324_385-413

Blackburn, R.T., \& Bentley, R.J. (1993). Faculty research productivity: Some moderators of associated stressors. Research in Higher Education, 34(6), 725-45. doi: 10.1007/BF00992157

Commission on Higher Education. (n.d.). Pathways to equity, relevance and advancement in research, innovation, and extension in Philippine higher education. Retrieved from https://ched.gov.ph/wpcontent/uploads/2017/10/CMO-52-s.-2016.pdf

Corbin, J., \& Strauss, A. (2015). Basics of qualitative research techniques and procedures for developing grounded theory (4th ed.). Los Angeles, CA: SAGE.

Creswell, J.W., \& Poth, C.N. (2018). Qualitative inquiry and research design. Choosing among five approaches (4th ed.). Thousand Oaks, CA: SAGE.

Fairweather, J. (2002). The mythologies of faculty productivity: Implications for institutional policy and decision making. DOI: 10.1353/jhe.2002.0006

Fairweather, J.S. (2002). The mythologies of faculty productivity: Implications for institutional policy and decision making. The Journal of Higher Education, 73(1), 26-48.

doi: $10.1353 /$ jhe.2002.0006

Gregorutti, G. (2011). Following the path from teaching to research university. Newcastle, England: Cambridge Scholars.

Hesli, V.L., \& Lee, J.M. (2011). Faculty research productivity: Why do some of our colleagues publish more than others? Retrieved from https://pdfs.semanticscholar.org/20df/795bf1d4f2ac483860db3cadbb29a299d004.pdf

Jacob, W.J., Gregorutti, G., Cummings, W.K., Finkelstein, M.J., Bain, O., \& Kim, E. (2020). Preferences of U.S. faculty members regarding the teaching-research nexus. Faculty Publications, 1504. Retrieved from https://digitalcommons.andrews.edu/pubs/1504

Jung, J. (2012). Faculty research productivity in Hong Kong across academic discipline. Higher Education Studies, 2(4), 1-13. Retrieved from https://files.eric.ed.gov/fulltext/EJ1081295.pdf

Khan, M.A. (2017). Achieving an appropriate balance between teaching and research in institutions of higher education: An exploratory study. International Journal of Information and Educational Technology, 7(5). Retrieved from http://www.ijiet.org/vol7/892-JR199.pdf

Lapoule, P., \& Lynch, R. (2018). The case study method: Exploring the link between teaching and research. Journal of Higher Education Policy and Management, 40(5). Doi.org/10.1080/1360080X.2018.1496515

Lea, M.R., \& Street, B.V. (1998). Student writing in higher education: An academic literacies approach. Studies in Higher Education, 23(2), 157-72. doi: 10.1080/03075079812331380364 
Lea, M.R., \& Street, B.V. (2006). The 'academic literacies' model: Theory and applications. Theory Into Practice, 45(4), 368-77. doi: 10.1207/s15430421tip4504_11

Lillis, T. (2003). Student writing as 'academic literacies': Drawing on Bakhtin to move from critique to design. Language and Education, 17(3), 192-207. doi: 10.1080/09500780308666848

Lillis, T., \& Scott, M. (2007). Defining academic literacies research: Issues of epistemology, ideology and strategy. Journal of Applied Linguistics, 4(1), 5-32. Retrieved from https://oro.open.ac.uk/17057/1/JAL_Lillis_and_Scott_pdf.pdf

Medallon, M.C. (2021). Teaching and learning in higher education: Perspectives of new millennium higher education learners (NML). LPL Research Journal, 2(1), 148-165. Retrieved from https://ejournals.ph/article.php?id=6700

Merriam, S.B. (1988). Case study research in education: A qualitative approach. Francisco, CA: JosseyBass.

Merriam, S.B. (2009). Qualitative research. A guide to design and implementation. Revised and expanded from Qualitative research and case study applications in education. San Francisco, CA: Jossey-Bass.

Merriam, S.B., \& Tisdell, E.J. (2016). Qualitative research: A guide to design and implementation (4th ed.). San Francisco, CA: Jossey-Bass.

Miles, D.A. (2017). A taxonomy of research gaps: Identifying and defining the seven research gaps. Retrieved from https://www.researchgate.net/publication/319244623_ARTICLE_Research_Methods_and_Strate gies_Workshop_A_Taxonomy_of_Research_Gaps_Identifying_and_Defining the Seven_Resear ch_Gaps\#: :text=This $\% 20$ article $\% 20$ will $\% 20$ introduce $\% 20$ the,Gaps $\% 20 \% 5$ Bsee $\% 20$ Figure $\% 20$ $1 \% 5$ D.\&text=Population $\% 2 \mathrm{C} \% 20$ (b) \%20Intervention\%2C,\%2C\%20and\%20(e)\%20Setting

Narbarte, M.P., \& Balila, J.S. (2018). Research involvement, motivation, and university initiatives as agents for enhancing research culture and quality. Catalyst, 17.

Nygaard, L.P. (2015). Publishing and perishing: An academic literacies framework for investigating research productivity. Studies in Higher Education, 42(3). Retrieved from https://www.tandfonline.com/doi/full/10.1080/03075079.2015.1058351?src=recsys

Rosaroso, R., Dakay, I., \& Sarmiento, R. (2015). Selected Philippine higher education institutions' perspectives on internationalization of education: Initiatives and guidelines. Asia Pacific Journal of Education, Arts and Sciences, 2(4), 41. Retrieved from www.apjeas.apjmr.com

Sax, L.J., Hagedorn, L.S., Arredondo, M., \& Dicrisi, F.A., III. (2002). Faculty research productivity: Exploring the role of gender and family-related factors. Research in Higher Education, 43(4), 423-446. Retrieved from https://link.springer.com/article/10.1023/A:1015575616285

Sheridan, J., Savoy, J.N., Kaatz, A., Lee, Y.G., Filut, A., \& Carnes, M. (2017). Write more articles, get more grants: The impact of department climate on faculty research productivity. Journal of Women's Health, 26(5), 587-596. Retrieved from https://www.ncbi.nlm.nih.gov/pmc/articles/PMC5446612/

Teodorescu, D. (2000). Correlates of faculty publication productivity: A cross-national analysis. Higher Education, 39, 201-22. doi: 10.1023/A:1003901018634

Wa-Mbaleka, S. (2015). Factors leading to limited faculty publications in Philippine higher education institutions. International Journal, 18(2), 121-141. Retrieved from https://internationalforum.aiias.edu/images/vol18no02/7SWa-Mbaleka.pdf

Williams, H.A., \& Kotrlik, J.W. (2004). A mediated hierarchical regression analysis of factors related to career research productivity of human resource education and development postsecondary faculty. In Academy of Human Resource Development International Conference (AHRD), 111926(Symp. 52-1). Austin, TX.

Yin, R.K. (2018). Case study research and applications. Los Angeles, CA: SAGE. 


\section{APPENDIX}

\section{Questions for the Online Open-Ended Survey}

\section{Faculty Research Production and Teaching}

Online Open-ended Survey

(for Faculty)

(Adapted from Gregorutti, 2011)

I have read and agreed with the Informed Consent Forum received through email from the researcher.

Yes (If not, please open your email and read it.)

Below are ten short open ended questions to facilitate your comments related to faculty research productivity and teaching. Please feel free to share anything related to your research productivity and teaching in your institution. At the end are five items related to your background. This survey will take $\mathbf{2 0}$ to 30 minutes to complete. Thank you for your cooperation in contributing to this study.

For the purpose of this survey, please use the following definitions:

Teaching: Class preparation, scheduled classroom instruction, grading, student advising

Research: Activity that leads to a publication (an article, report, review, monograph, book, grant proposal).

1. What reasons do you have to publish (better teaching, knowledge advancement, resources, etc.)? Please number the items as you list them.

2. Do you consider yourself a successful researcher (journal, books, conferences)? Why yes or no?

3. What would help you be a productive researcher?

4. What institutional/departmental characteristics would help you to produce more research?

5. Do you think that your department promotes and mentors faculty research productivity? Why yes or no?

6. Do you think your institution should refocus toward more research? Why yes or no?

7. Do you consider yourself as balancing research productivity and teaching? Why yes or no?

8. If the answer to Q. 7 is yes, what are ways or strategies that you use for balancing research production and teaching?

9. If the answer to Q. 7 is no, what are the reasons?

10. Are there any other comments on these issues you would like to make?

\section{Demographic Information}

1. In what department is your primary appointment?

2. What is your gender?

3. What is your current academic rank?

4. What is your current teaching load (in terms of full time teaching or part time teaching)

5. Are you currently engaged in any administrative responsibilities? 
TABLE 1

DATA TRIANGULATION MATRIX

\begin{tabular}{lccccc}
\hline Research Questions & $\begin{array}{c}\text { Open- } \\
\text { ended } \\
\text { Survey }\end{array}$ & $\begin{array}{l}\text { Individual } \\
\text { Interviews }\end{array}$ & $\begin{array}{c}\text { Focus Group } \\
\text { Discussions }\end{array}$ & Documents & Literature \\
\hline $\begin{array}{l}\text { 1. What makes faculty } \\
\text { members produce and publish } \\
\text { more research? }\end{array}$ & $\checkmark$ & $\checkmark$ & $\checkmark$ & $\checkmark$ & $\checkmark$ \\
\hline $\begin{array}{l}\text { 2. What personal } \\
\text { characteristics foster or } \\
\text { inhibit faculty research } \\
\text { production? }\end{array}$ & $\checkmark$ & $\checkmark$ & $\checkmark$ & $\checkmark$ \\
\hline $\begin{array}{l}\text { 3. What institutional } \\
\text { characteristics foster or } \\
\text { inhibit faculty research } \\
\text { production? }\end{array}$ & $\checkmark$ & $\checkmark$ & $\checkmark$ & $\checkmark$ \\
\hline $\begin{array}{l}\text { 4. How do faculty members } \\
\text { balance the teaching and } \\
\text { research production } \\
\text { opportunities of the } \\
\text { institution? }\end{array}$ & $\checkmark$ & $\checkmark$ & $\checkmark$ & $\checkmark$ \\
\hline
\end{tabular}

Question 5. Do you think your institution should refocus toward more research?

A majority of the respondents (81.8\%) voted "yes" to the question. The reasons given included, "Research is the future of the institution. In addition, when faculty publishes it gives a positive image to the institution," "Research is the power source for dynamism in the institution," ". . this will give value to faculty," and ". . .cannot be credible in guiding students' research if its own faculty do not prove they are qualified and able to do research." A "more articulated policy on publication" was seen as improving faculty research productivity. The institution becoming a publisher was also suggested in order to "publish books with its teachers as authors."

Responses against research thrust of faculty were also found. Pointing to the need to emphasis teaching, and for minimizing the tension between being a research university and academic university, a faculty mentioned, "While research builds credibility for the professor and for the institution, we also have a mandate to provided leadership training for the world field." 